\title{
Kinetics of Free Fatty Acid Esterification in Used Cooking Oil Using Hypercrosslinked Exchange Resin as Catalyst
}

\author{
Sumaiya Zainal Abidin, Goran Vladisavljevic, and Basudeb Saha
}

\begin{abstract}
A kinetic study of free fatty acid esterification was carried out using Purolite D5081 as a catalyst. Esterification reaction was carried out using $1.25 \%(\mathrm{w} / \mathrm{w})$ catalyst loading, $6: 1$ methanol to oil feed mole ratio, $350 \mathrm{rpm}$ stirring speed and reaction temperatures ranging from 323 - $335 \mathrm{~K}$. The experimental data from the esterification reaction were fitted to three kinetic models: Pseudo Homogeneous (PH), Eley-Rideal(ER) and Langmuir-Hinshelwood-Hougen-Watson (LHHW) models. A built-in ODE45 solver in MATLAB 7.0 was used to numerically integrate the differential molar balances describing the concentration of FFA in the system. The influence of temperature on the kinetic constants was determined by fitting the results to the Arrhenius equation. Experimental data were successfully fitted by the $\mathrm{PH}$ model and a good agreement between the experimental and the calculated moles of FFA were observed for all the experimental data points. The activation energies for the esterification and hydrolysis reactions were found to be 53 and $107 \mathrm{~kJ} / \mathrm{mol}$, respectively. These results proved that the hydrolysis reverse reaction requires more energy to occur as compared to esterification reaction, hence validated the proposed model.
\end{abstract}

Index Terms-Biodiesel, esterification, free fatty acids, kinetic modeling.

\section{INTRODUCTION}

Fatty acid methyl ester (FAME), or commercially known as biodiesel is an alternative energy that derived from renewable lipid feedstocks. Biodiesel is considered to be one of the best available energy resources as it shows a good combustion emission profile, produces less particulates and hazardous gases, have a higher cetane number, higher flash point and a higher lubricity as compared to conventional diesel. However, the main limitation of biodiesel production was due to the relatively high cost of raw material, comprises more than $75 \%$ of the total cost [1]. Therefore, sources such as non-edible feedstocks (i.e. non-edible oil, animal fats and waste oils) are found to be the most promising alternative to replace edible feedstocks. Most of the non-edible feedstocks contain significant amounts of free fatty acids (FFA). Oils

Manuscript received July 27, 2015; revised January 27, 2016. This work was supported in part by the Purolite Int. Ltd., Loughborough University, United Kingdom, GreenFuel Oil Co. Ltd., United Kingdom and Ministry of Education, Malaysia.

Sumaiya Zainal Abidin is with the Faculty of Chemical and Natura Resources Engineering \& Centre of Excellence for Advanced Research in Fluid Flow (CARIFF), Universiti Malaysia Pahang, Lebuhraya Tun Razak, 26300 Gambang, Kuantan, Pahang Darul Makmur, Malaysia (e-mail: sumaiya@ump.edu.my).

Goran Vladisavljevic was with the Department of Chemical Engineering, Loughborough University, Loughborough, Leicestershire, LE11 3TU, United Kingdom (e-mail: g.vladisavljevic@lboro.ac.uk).

Basudeb Saha is with the Department of Applied Science, Faculty of Engineering, Science and Built Environment, London South Bank University, London, SE 0AA, United Kingdom (e-mail: b.saha@1sbu.ac.uk). and fats with high FFA content (i.e.>1\%) cannot be directly used in a base catalysed transesterification reaction as the side reaction; saponification process hinders the separation of esters from glycerine. High yield could be achieved using a two-step synthesis of biodiesel and acid catalysed esterification is always preferable as a pre-treatment step to reduce the large amount of FFA in the feedstock.

The use of heterogeneous catalysts simplifies the production and purification processes because they can be easily separated from the reaction mixture, allowing multiple usage of the catalyst through regeneration process. Ion exchange resins in particular, have become more popular due to the capability of catalysing both esterification and transesterification reaction under mild conditions and it can be easily separated and recovered from the product mixture. Reference [2] studied the performance of two different macroeticular cation exchange catalysts, the Amberlyst-15 and Amberlyst BD20. They found that the amount of pores of the catalyst played an important role, not only in increasing the catalytic activity, but also in reducing the inhibition of water in the esterification process. New development on the polymerization techniques has led to the formulation of hypercrosslinked marcroporous cation exchange resin, which capable to catalyse reaction processes much faster due to the presence of higher specific surface area Reference [3] studied on the esterification of free fatty acids in used cooking oil using hypercrosslinked exchange resin, Purolite D5081 as catalyst. This resin was found to give the highest FFA conversion ( $92 \%)$ in less than 4 hours.

Kinetic studies of the esterification reaction have been conducted for both homogeneous and heterogeneous catalysts. Several studies on kinetic models have been conducted using single fatty acid esterification (e.g. lactic acid, myristic acid and palmitic acid) with different kinds of ion exchange resins. Reference [4] studied the kinetics of lactic acid esterification reaction with methanol $(\mathrm{MeOH})$, catalysed by different acidic resins, such as Dowex 50W8x, Dowex 50W2x, Amberlyst 36 and Amberlyst 15 dry. They used three types of kinetic models, QH, ER and LHHW, to correlate the experimental data. The $\mathrm{QH}$ model was found to fit the experimental data well since the reaction medium reported was a highly polar mixture. Similar work on lactic acid esterification was carried out by Reference [5] with iso-butanol and n-butanol as solvent and Weblyst D009 as a catalyst. Experimental data was correlated using the same kinetic models (PH, LHHW and ER). All models showed a reasonably good results but the $\mathrm{PH}$ model was preferred due to its simple mathematical model (Qu et al., 2009).

Investigation of the kinetic modelling of free fatty acids (FFA) esterification in waste oils was carried out by several researchers. For instance, Reference [6] investigated on the 
esterification of FFA in used vegetable oils using Purolite CT-275. They correlated their experimental data using PH model and good agreement was obtained between the experimental data and calculated values. Using the same PH model, they successfully predicted the optimum conversion of two other oils with higher FFA content. A kinetic study of FFA esterification in low grade crude palm oil was investigated by reference [7]. Results revealed that the reaction was irreversible and followed a first order kinetic law. Reference [8] studied the kinetic of FFA esterification in waste cooking oil with $\mathrm{Fe}_{2}\left(\mathrm{SO}_{4}\right)_{3} / \mathrm{C}$ as a catalyst and the experimental data were modelled using the LHHW kinetic model. They found that the proposed kinetic model was favourably consistent with the experimental results.

On the other hand, there are several kinetic models conducted on artificially modified feedstock, ideally made to investigate the performance of ion exchange resin catalysts in highly acidified oil. For example, Reference [9] studied the reaction kinetics of oleic acid esterification in triglycerides using the sulfonic acid resin (Relite CFS) as catalyst. They modelled the reaction kinetics using the PH model (second order reaction) and the experimental data was found to have a satisfactory agreement with the calculated values. This research work has been extended by Reference [10] using Amberlyst 15 as a catalyst with two different reaction configurations; the batch stirred tank reactor and bed loop reactor. Two types of kinetic models ( $\mathrm{PH}$ and ER) were compared and it was found that the ER model was a superior model as compared to the $\mathrm{PH}$ model for the esterification of high FFA oil. The kinetic model of myristic acid esterification in the presence of triglycerides using sulfated zirconia as a catalyst was investigated by Reference [11]. A second order reversible PH model was demonstrated to fit the experimental data and this model gave a satisfactory interpretation of the experimental data. A similar finding was reported by Reference [12] when they investigated the esterification of myristic acid using homogeneous ( $p$-toulene sulfonic acid) and heterogeneous (Amberlyst 15 and Degussa) catalysts. Their experimental data have been interpreted with a second order kinetic model and a good agreement was achieved between the experimental data and the model.

In this research work, a detailed study on the kinetic behaviour of FFA esterification using Purolite D5081 as catalyst was carried out. Several kinetic models have been investigated: the PH, LHHW and ER models. Previously, effect of mass transfer resistances showed that the reaction was not affected by the mass transfer resistances [3]. Therefore in this kinetic study, external and internal mass transfer limitation is considered to be negligible and hence not considered. In the same study, they also found that the rate of non-catalysed reaction was negligible relative to the catalysed reaction. Kinetic parameters such rate constant and adsorption coefficient were determined using MATLAB using the built-in ODE45 solver (fourth order Runge-Kutta method) to solve the differential equations numerically. The best fitted model was further investigated to determine the activation energy of the esterification reaction.

\section{KINETIC MODELING OF FFA ESTERIFICATION}

The experimental work on the esterification process was carried out in a jacketed-glass reactor and the findings have been reported by Reference [3]. For the kinetic studies of FFA esterification, several kinetic models have been proposed i.e. the PH, LHHW and ER models. The PH kinetic model was built based on the following assumptions; i) $\mathrm{MeOH}$ to FFA molar ratio used was very high, and therefore $\mathrm{MeOH}$ concentration was assumed to be constant ii) the diffusion rate of reactants and products onto the catalyst surface assumed to be negligible iii) there was no fatty acid methyl ester (FAME) present in the reaction at time, $t=0$.

For the heterogeneous models (LHHW and ER), a reaction-on-surface kinetics and rate law were developed based on the following assumptions i) the adsorption of $\mathrm{MeOH}, \mathrm{H}_{2} \mathrm{O}$, FFA and FAME occurs on the surface of the resins. Triglycerides are considered to be non-adsorbing compounds ii) For LHHW model, the rate determining step is controlled by the surface reaction with dual site adsorption mechanism and for ER model, a single site adsorption mechanism is been considered iii) the adsorption equilibrium constants are assumed to be independent of the reaction temperature in the investigated temperature range iv) there was no fatty acid methyl ester (FAME) present in the reaction at time, $t=0$.

It was proposed that for $\mathrm{PH}$ model, the reaction was a pseudo $\mathrm{n}$ order in the forward reaction and second order in the reverse reaction. Therefore, based on these assumptions, the following kinetic rate law was derived.

$$
\text { PH model }\left(-r_{A}\right)=\left(k_{f}^{\prime} C_{A}\right)^{n}-\left(-k_{r} C_{C} C_{D}\right)
$$

where $-r_{A}$ is the reaction rate of FFA, $C_{A}, C_{B}, C_{C}$ and $C_{D}$ are the concentration of FFA, MeOH, FAME and water $\left(\mathrm{H}_{2} \mathrm{O}\right)$ in the reaction mixture, $k_{f}^{\prime}=k_{f} \times C_{B}, 0, k_{f}$ and $k_{r}$ are the reaction rate constant for forward (esterification) and reverse (hydrolysis) reaction and $\mathrm{n}$ is the order of forward reaction.

For both heterogeneous model (LHHW and ER), it was proposed that the reaction is second order for forward and reverse reactions. For an esterification reaction sequence based on the LHHW model, the mechanism involves the chemisorption of FFA and $\mathrm{MeOH}$ as molecules, followed by a reaction between chemisorbed FFA and $\mathrm{MeOH}$ molecules to form FAME and $\mathrm{H}_{2} \mathrm{O}$ molecules, and finally the desorption of FAME and $\mathrm{H}_{2} \mathrm{O}$. For an esterification reaction sequence based on the ER model, the reaction mechanism differs in terms of the components which are adsorbed onto the catalyst. There are two possible cases for ER model; ER model (Case I) where the adsorbed $\mathrm{MeOH}$ is reacting with FFA in the fluid and ER model (Case II) where the adsorbed FFA reacts with $\mathrm{MeOH}$ in the fluid. The rate equation for LHHW and ER models can be expressed as:

LHHW model:

$$
\left(-r_{A}\right)=\frac{k_{f} K_{A} K_{B}\left(C_{A} C_{B}-\frac{1}{K} C_{C} C_{D}\right)}{\left(1+K_{A} C_{A}+K_{B} C_{B}+K_{C} C_{C}+K_{D} C_{D}\right)^{2}}
$$

ER model (Case I):

$$
\left(-r_{A}\right)=\frac{k_{f} K_{B}\left(C_{A} C_{B}-\frac{1}{K} C_{C} C_{D}\right)}{\left(1+K_{B} C_{B}+K_{D} C_{D}\right)}
$$


ER model (Case II):

$$
\left(-r_{A}\right)=\frac{k_{f} K_{A}\left(C_{A} C_{B}-\frac{1}{K} C_{C} C_{D}\right)}{\left(1+K_{A} C_{A}+K_{C} C_{C}\right)}
$$

where $-r_{A}$ is the reaction rate of FFA, $C_{A}, C_{B}, C_{C}$ and $C_{D}$ are the concentration of FFA, $\mathrm{MeOH}$, FAME and $\mathrm{H}_{2} \mathrm{O}$ in the reaction mixture, $K_{A}, K_{B}, K_{C}$ and $K_{D}$ are the adsorption equilibrium constants for species $\mathrm{A}, \mathrm{B}, \mathrm{C}$ and D respectively and formulated from the ratio of the adsorption and desorption rate constant, $K_{i}=k_{a} / k_{d}, \quad K=\left(K_{A} K_{B} / K_{C} K_{D}\right) K_{e}$ for LHHW model, $K=\left(K_{B} / K_{D}\right) K_{e}$ for Case I ER model and $K=\left(K_{A} / K_{C}\right) K_{e}$ for Case II ER model, $K_{e}=k_{f} / k_{r}=\left(\left(K_{C} / K_{A}\right) \times\right.$ $\left.\left(K_{D} / K_{B}\right)\right) \times\left(\left(C_{C} / C_{A}\right) \times\left(C_{D} / C_{B}\right)\right)$ for LHHW model, $K_{e}=k_{f} / k_{r}=\left(K_{D} / K_{B}\right) \times\left(\left(C_{C} / C_{A}\right) \times\left(C_{D} / C_{B}\right)\right)$ for Case I ER model and $K_{e}=k_{f} / k_{r}=\left(K_{C} / K_{A}\right) \times\left(\left(C_{C} / C_{A}\right) \times\left(C_{D} / C_{B}\right)\right)$ for Case II ER model, $k_{f}$ and $k_{r}$ are the reaction rate constant for forward (esterification) and reverse (hydrolysis) reaction.

Depending on the kinetic model, two reaction rate constants $k_{f}$ and $k_{r}$ and up to four adsorption coefficient $\left(K_{A}\right.$, $K_{B}, K_{C}$ and $K_{D}$ ) are unknown. These unknowns must be determined to describe the reaction system. A built-in ODE45 solver in MATLAB 7.0 was used to numerically integrate the differential molar balances describing the concentration of FFA in the system. Optimum kinetic parameters were determined by minimising the sum of residual squares (SRS) between experimental and calculated moles of FFA.

\section{RESULTS AND DISCUSSIONS}

TABLE I: FORWARD AND REVERSE RATE CONSTANTS VALUES FOR LHHW AND ER (CASE I AND II) MODELS

\begin{tabular}{ccc}
\hline $\begin{array}{c}\text { Models/ } \\
\text { Temp, (K) }\end{array}$ & $\begin{array}{c}\text { Forward Rate } \\
\text { Constant, } k_{f}\end{array}$ & $\begin{array}{c}\text { Reverse Rate } \\
\text { Constant, } k_{r}\end{array}$ \\
\hline \multicolumn{3}{c}{ Langmuir-Hinshelwood-Hougen-Watson } \\
323 & 0.5440 & 0.00124 \\
328 & 0.7110 & 0.00130 \\
333 & 0.8150 & 0.00091 \\
& 0.7620 & 0.00086 \\
323 & Eley Rideal (Case I) \\
328 & 0.0084 & 0.00006 \\
333 & 0.1810 & 0.00004 \\
335 & 0.0015 & 0.00005 \\
323 & 0.0008 & 0.00012 \\
328 & Eley Rideal (Case II) & \\
333 & 4.3900 & 0.06700 \\
335 & 2.4000 & 0.10100 \\
Units for forward and reverse rate contants are $\mathrm{kg}^{2} \mathrm{~kg}_{\text {cat }}^{-1} \mathrm{~mol}^{-1} \mathrm{~s}^{-1}$.
\end{tabular}

Experimental data were successfully fitted by the $\mathrm{PH}$ model whereas results obtained from both heterogeneous kinetic models gave negative values for adsorption coefficients. The fitted values for heterogeneous models are given in Table I and Table II. As some of the adsorption coefficients give negative values, the results would be meaningless and hence they were not considered. Furthermore, from the ER model (Case I) route, the mechanism shows that this model cannot lead to reaction and the inhibition was due to the competition of active sites between the reactants. Reference [13] revealed similar findings when they developed several kinetic models for the synthesis of n-hexyl acetate. It was concluded that the heterogeneous kinetic models failed to correctly describe the reaction kinetics. For this analysis, PH model was chosen for further analysis since both LHHW and ER models were unable to predict the experimental data.

TABLE II: ADSORPTION COEFFICIENT VALUES FOR LHHW AND ER (CASE I AND II) MODELS

\begin{tabular}{|c|c|c|c|c|}
\hline \multirow{2}{*}{$\begin{array}{c}\text { Models/ } \\
\text { Temp, (K) }\end{array}$} & \multicolumn{4}{|c|}{ Adsorption Coefficient } \\
\hline & $K_{A}$ & $K_{B}$ & $K_{C}$ & $K_{D}$ \\
\hline \multicolumn{5}{|c|}{ Langmuir-Hinshelwood-Hougen-Watson } \\
\hline 323 & 606.00 & -78.30 & 83.90 & -132.0 \\
\hline 328 & 656.00 & -83.30 & 106.0 & -133.0 \\
\hline 333 & 452.00 & -50.90 & 119.0 & -82.90 \\
\hline 335 & 478.00 & -46.20 & 85.20 & -60.90 \\
\hline \multicolumn{5}{|c|}{ Eley Rideal (Case I) } \\
\hline 323 & $\mathrm{n} / \mathrm{a}$ & -0.081 & $\mathrm{n} / \mathrm{a}$ & -2.21 \\
\hline 328 & $\mathrm{n} / \mathrm{a}$ & -0.042 & $\mathrm{n} / \mathrm{a}$ & -1.21 \\
\hline 333 & $\mathrm{n} / \mathrm{a}$ & -0.072 & $\mathrm{n} / \mathrm{a}$ & -2.29 \\
\hline 335 & $\mathrm{n} / \mathrm{a}$ & -0.084 & $\mathrm{n} / \mathrm{a}$ & -1.01 \\
\hline \multicolumn{5}{|c|}{ Eley Rideal (Case I) } \\
\hline 323 & -0.0002 & $\mathrm{n} / \mathrm{a}$ & -0.230 & $\mathrm{n} / \mathrm{a}$ \\
\hline 328 & -0.0005 & $\mathrm{n} / \mathrm{a}$ & -0.177 & $\mathrm{n} / \mathrm{a}$ \\
\hline 333 & -0.0004 & $\mathrm{n} / \mathrm{a}$ & -0.339 & $\mathrm{n} / \mathrm{a}$ \\
\hline 335 & -0.0008 & $\mathrm{n} / \mathrm{a}$ & -0.222 & $\mathrm{n} / \mathrm{a}$ \\
\hline
\end{tabular}

For this analysis, PH model was chosen for further analysis since both LHHW and ER models were unable to predict the experimental data. Fig. 1 shows the moles of FFA versus reaction time profile for the esterification performed at different reaction temperatures. From Fig. 1(a), a good agreement between the experimental and the calculated moles of FFA were observed for all the experimental data points. The pseudo order for forward reaction was found to give the optimum value of $n=1.6$. The calculated results for the PH model kinetic parameters are summarized in Table III. The forward and reverse rate constants, $k_{f}$ and $k_{r}$ increased with an increase in reaction temperature (see Table III). However, the increase of reverse rate constant, $k_{r}$ values with the increase of reaction temperature are considered to be very small and this indicates that the reverse reaction, the hydrolysis process was hardly took place in the reaction.

The influence of reaction temperature on the reaction rate was determined by fitting the rate constant, $k_{f}$ and $k_{r}$ to the Arrhenius-Van't Hoff equation. The Arrhenius plot for the esterification of FFA with $\mathrm{MeOH}$ is shown in Fig. 1 (b). The activation energies for the esterification and hydrolysis reactions were found to be 53 and $107 \mathrm{~kJ} / \mathrm{mol}$, respectively. The reported activation energy values are in good agreement with those values reported in the literature for similar systems, with the consideration that different reaction system, temperature range, type of catalyst and catalyst loading were involved.

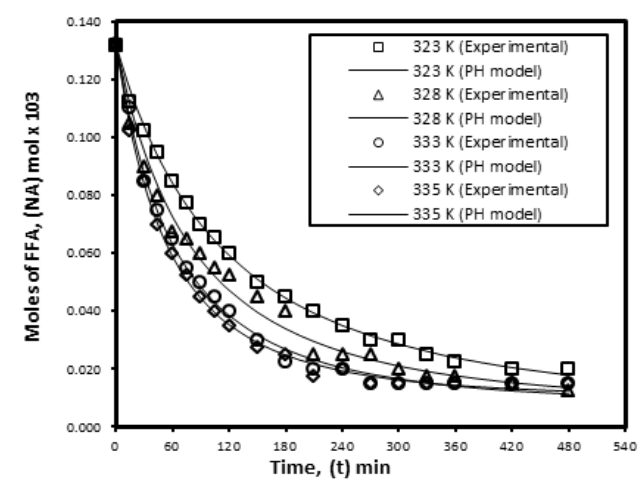




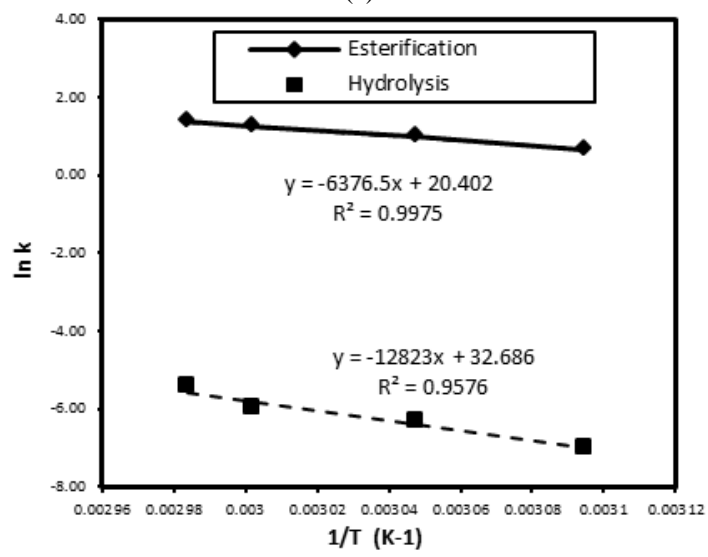

(b)

Fig. 1. (a) The effect of reaction temperatures on the moles of FFA; (b) The Arrhenius plot for the esterification of FFA using Purolite D5081 as a catalyst.

TABLE III: ESTIMATED VALUES OF THE RATE CONSTANTS (FORWARD AND REVERSE REACTION) AND THE CORRESPONDING VALUES OF SRS FOR PH

\begin{tabular}{|c|c|c|c|c|}
\hline $\begin{array}{l}\text { Temp, } \\
\mathrm{T}(K)\end{array}$ & $\begin{array}{c}\text { Forward Rate } \\
\text { Constant, } k_{f} \\
(\mathrm{~kg} 2.6 \mathrm{kgcat}-1 \\
\text { mol-1.6 s-1) }\end{array}$ & $\begin{array}{l}\text { Reverse Rate } \\
\text { Constant, } k_{r} \\
\text { (kg2 kgcat-1 } \\
\text { mol-1 s-1) }\end{array}$ & $\begin{array}{l}\text { Sum of } \\
\text { Residual } \\
\text { Square } \\
\text { (SRS) }\end{array}$ & $\begin{array}{l}\text { Equilibrium } \\
\text { Constant, } K_{e q}\end{array}$ \\
\hline 323 & 1.9302 & $9.10 \mathrm{E}-04$ & $3.79 \mathrm{E}-05$ & 2121.13 \\
\hline 328 & 2.7003 & 1.79E-03 & 2.47E-04 & 1510.01 \\
\hline 333 & 3.5000 & $2.51 \mathrm{E}-03$ & $1.04 \mathrm{E}-04$ & 1394.46 \\
\hline 335 & 3.9500 & 4.31E-03 & $4.59 \mathrm{E}-05$ & 917.18 \\
\hline
\end{tabular}

\section{CONCLUSION}

The kinetic modelling of FFA esterification was successfully carried out using Purolite D5081 as a catalyst. Esterification reaction was carried out using $1.25 \%(\mathrm{w} / \mathrm{w})$ catalyst loading, 6:1 MeOH: UCO feed mole ratio, $350 \mathrm{rpm}$ stirring speed and reaction temperatures ranging from 323 $335 \mathrm{~K}$. The experimental data from the esterification reaction were fitted to three kinetic models: PH, LHHW and ER. From the simulation results, it was found that both heterogeneous kinetic models gave negative values for the adsorption coefficients and hence were not considered further. Experimental data was successfully represented by the PH model and good agreement between the experimental and the calculated values was obtained. The pseudo order for forward reaction was found to give the optimum value of $n=1.6$. The forward rate constant, $k_{f}$ increased with an increase in reaction temperature. However, the increase of reverse rate constant, $k_{r}$ values with the increase in reaction temperature are considered to be very small and this indicates that the reverse reaction (hydrolysis process) hardly took place in the reaction. The activation energies for the esterification and hydrolysis reactions were found to be 53 and $107 \mathrm{~kJ} / \mathrm{mol}$, respectively. These results proved that the hydrolysis reverse reaction requires more energy to occur as compared to esterification reaction, hence validated the proposed model.

\section{ACKNOWLEDGMENT}

We gratefully acknowledge Purolite International Ltd. (late Dr. Jim Dale and Mr. Brian Windsor) for kindly supplying the catalysts for this research work and GreenFuel Oil Co. Ltd. for supplying the UCO. We would like to acknowledge UMP research grant RDU130311 for the conference budget allocation.

\section{REFERENCES}

[1] E. Atabani, A. S. Silitonga, I. A. Badruddin, T. M. I. Mahlia, H. H Masjuki, and S. A. Mekhilef, "Comprehensive review on biodiesel as an alternative energy resource and its characteristics," Renew. Sust. Energ. Rev., vol. 16, pp. 2070-2093, May 2012.

[2] J. Y. Park, D. G. Kim, and J. S. Lee, "Esterification of free fatty acids using water-tolerable Amberlyst as a heterogeneous catalyst," Bioresour. Tech., vol. 101, pp. S62-S65, Jan. 2010.

[3] S. Z. Abidin, K. F. Haigh, B. Saha, and G. Vladisavljević, "Esterification of free fatty acids in used cooking oil using ion-exchange resins as catalysts: An efficient pretreatment method for biodiesel feedstock," Ind. Eng. Chem. Res., vol. 51, pp. 14653-14664, Oct. 2012.

[4] M. T. Sanz, R. Murga, S. Beltrán, and J. L. Cabezas, “Autocatalyzed and ion-exchange-resin-catalyzed esterification kinetics of lactic acid with methanol," Ind. Eng. Chem. Res., vol. 41, pp. 512-517, Jan. 2002.

[5] Y. Qu, S. Peng, S. Wang, Z. Zhang, and J. Wang, "Kinetic study of esterification of lactic acid with isobutanol and n-butanol catalyzed by ion-exchange resins," Chi. J. Chem. Eng., vol. 1, pp. 773-780, Oct. 2009.

[6] S. Pasias, N. Barakos, C. Alexopoulos, and N. Papayannakos, "Heterogeneously catalyzed esterification of FFAs in vegetable oils," Chem. Eng. Tech., vol. 29, pp. 1365-71, Oct. 2006.

[7] Satriana and D. Supardan, "Kinetic study of esterification of free fatty acid in low grade crude palm oil using sulfuric acid," Asean J. Chem. Eng., vol. 8, pp. 1-8, Dec. 2008.

[8] M. Gan, D. Pan, L. Ma, E. Yue, and J. Hong, "The kinetics of the esterification of free fatty acids in waste cooking oil using $\mathrm{Fe}_{2}\left(\mathrm{SO}_{4}\right)_{3} / \mathrm{C}$ catalyst," Chi. J. Chem. Eng., vol. 17, pp. 83-87, Feb. 2009.

[9] R. Tesser, M. Di Serio, M. Guida, M. Nastasi, and E. Santacesaria, "Kinetics of oleic acid esterification with methanol in the presence of triglycerides," Ind. Eng. Chem. Res., vol. 44, pp. 7978-7982, Sept. 2005 .

[10] R. Tesser, L. Casale, D. Verde, M. Di Serio and E. Santacesaria, "Kinetics of free fatty acids esterification: Batch and loop reactor modelling," Chem. Eng. J., vol. 154, pp. 25-33, Nov. 2009.

[11] D. Rattanaphra, A. P. Harvey, A. Thanapimmetha, and P. Srinophakun, "Kinetic of myristic acid esterification with methanol in the presence of triglycerides over sulfated zirconia," Renew. Energ., vol. 36, pp. 2679-2686, 2011.

[12] T. Yalçinyuva, H. D. Boz, and M. A. Guerkaynak, "Kinetics and mechanism of myristic acid and isopropyl alcohol esterification reaction with homogeneous and heterogeneous catalysts," Int. J. Chem. Kinet., vol. 40, pp. 136-144, March 2008.

[13] M. Schmitt and H. Hasse, "Chemical equilibrium and reaction kinetics of heterogeneously catalysed n-hexyl acetate esterification," Ind. Eng. Chem. Res., vol. 45, pp. 4123-4132, May 2006.

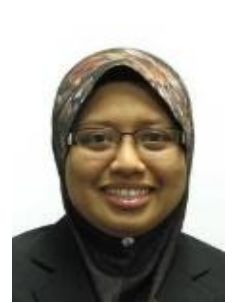

Sumaiya Zainal Abidin was born in Sheffield, United Kingdom in 1981. She received the B.Eng. and MSc. degree in chemical engineering from University Putra Malaysia, Malaysia in 2004 and 2006. She received her $\mathrm{Ph} . \mathrm{D}$. degrees in chemical engineering from Loughborough University, United Kingdom in year 2012 .

In 2006, she joined the Department of Chemical and Natural Resources Engineering, University Malaysia Pahang, Malaysia, as a lecturer, and in 2012 became a senior lecturer. Her current research interests include renewable energy, biodiesel and biofuels, reaction engineering, catalysis, separation engineering, hydrometallurgy, crystallization, rare earth technology and pharmaceutical engineering.

Dr. Abidin is currently a member of IChemE (Malaysia) and also a member of Board of Engineer (Malaysia). She has been publishing in various impact factor journals, secured various international and national research grant and won several awards from research and academic field. 